Original Contribution

\title{
Chloroquine-induced glioma cells death is associated with mitochondrial membrane potential loss, but not oxidative stress
}

\author{
Alexandre Teixeira Vessoni ${ }^{a}$, Annabel Quinet ${ }^{a}$, Leonardo Carmo de Andrade-Lima ${ }^{a}$, \\ Davi Jardim Martins ${ }^{a}$, Camila Carrião Machado Garcia ${ }^{b}$, Clarissa Ribeiro Reily Rocha ${ }^{a}$, \\ Debora Braga Vieira ${ }^{a}$, Carlos Frederico Martins Menck ${ }^{a, *}$ \\ a Departamento de Microbiologia, Instituto de Ciências Biomédicas, Universidade de São Paulo, Avenida Professor Lineu Prestes, 1374, 05508-000 São Paulo, \\ SP, Brazil \\ ${ }^{\mathrm{b}}$ Núcleo de Pesquisa em Ciências Biológicas \& Departamento de Ciências Biológicas, Instituto de Ciências Exatas e Biológicas, Universidade Federal de Ouro \\ Preto, Campus Morro do Cruzeiro, Ouro Preto, 35400-000 Minas Gerais, MG, Brazil
}

\section{A R T I C L E I N F O}

\section{Article history:}

Received 29 September 2015

Accepted 4 November 2015

Available online 11 November 2015

\section{Keywords:}

Glioma

Chloroquine

Mitochondrial membrane potential

Oxidative stress

Glutathione

Autophagy

\begin{abstract}
A B S T R A C T
Chloroquine (CQ), a quinolone derivative widely used to treat and prevent malaria, has been shown to exert a potent adjuvant effect when combined with conventional glioblastoma therapy. Despite inducing lysosome destabilization and activating p53 in human glioma cells, the mechanisms underlying cell death induced by this drug are poorly understood. Here, we analyzed in a time- and dose-dependent manner, the effects of CQ upon mitochondria integrity, autophagy regulation and redox processes in four human glioma cell lines that differ in their resistance to this drug. NAC-containing media protected cells against CQ-induced loss of mitochondrial membrane potential (MMP), autophagic vacuoles (LC3II) accumulation and loss of cell viability induced by CQ. However, we noticed that part of this protection was due to media acidification in NAC preparations, alerting for problems in experimental procedures using NAC. The results indicate that although CQ induces accumulation of LC3II, mitochondria, and oxidative stress, neither of these events is clearly correlated to cell death induced by this drug. The only event elicited in all cell lines at equitoxic doses of CQ was the loss of MMP, indicating that mitochondrial stability is important for cells resistance to this drug. Finally, the data indicate that higher steady-state MMP values can predict cell resistance to CQ treatment.
\end{abstract}

(c) 2015 Elsevier Inc. All rights reserved.

\section{Introduction}

In the United States, there are 20.59 cases of primary brain and central nervous system (CNS) tumors per 100,000 individuals per year [1], and gliomas account for $80 \%$ of these malignant tumors [2]. Gliomas are classified according to their cell type of origin (astrocytoma, oligodendroma or ependymoma) and their brain infiltration capacity $[2,3]$. According to the WHO, glioblastoma multiforme (GBM), the most malignant and common astrocytoma, is classified as a grade IV astrocytoma (very aggressive and with greater fatality compared with other lower grade, less aggressive

\footnotetext{
Abbreviations: AVs, autophagic vacuoles; MMP, mitochondrial membrane potential; $\mathrm{CQ}$ chloroquine; CNS, central nervous system; GBM, glioblastoma multiforme; MMP, mitochondrial membrane potential; NAC, N-acetyl L-cysteine

* Corresponding author.

E-mail addresses: alexandre.vessoni@usp.br (A.T. Vessoni), annabel.quinet@usp.br (A. Quinet), leolima11@gmail.com (L.C.d. Andrade-Lima), carriao.camila@gmail.com (C.C.M. Garcia), calsmah@yahoo.com.br (C.R.R. Rocha), deborabv@hotmail.com (D.B. Vieira), cfmmenck@usp.br (C.F.M. Menck).
}

gliomas) [4]. Characteristics of GBM include tissue necrosis, highly proliferative and invasive cells, and pronounced angiogenesis $[3,4]$. GBM can originate through de novo pathway (no evidence of prior symptoms and usually affecting patients 45 years old or older), or through a progressive pathway (patients usually younger than 45) in which GBM originates from the progressive transformation of lower grade gliomas $[3,5]$.

GBM treatment includes surgical resection, chemotherapy with alkylating and chloroethylating agents (such as temozolomide and carmustine), and radiotherapy [6]. The "gold standard" protocol includes surgical resection followed by combined radiation and temozolomide treatment [7]. However, despite an aggressive multimodal therapy, the median patient survival time is only $12-$ 15 months. Therefore, an understanding of GBM tumor and cell biology is urgently needed to identify new potential therapeutic approaches.

Chloroquine (CQ), a lysosomotropic drug widely used in malaria treatment, has been shown to improve the median survival time of patients undergoing conventional glioblastoma therapy. Patients who received $\mathrm{CQ}$ in addition to therapy had a mean 
survival time of 27 months, compared with 11 months for patients in the control group [8,9].

At the cellular level, CQ was shown to cause lysosome membrane permeabilization, and is therefore widely used to block autophagy, a lysosome-dependent degradation pathway that has been implicated in the resistance of cancer cells to chemo and radiotherapy possibly through the recycling of damaged and/or superfluous proteins and organelles, such as dysfunctional mitochondria, whose accumulation can be toxic to cells [10-14]. Recent investigation in vitro on glioma cells revealed that CQ causes the accumulation of unprocessed autophagic vacuoles (AVs), with the subsequent release of cathepsins into the cytosol, followed by the activation of p53 and caspase- 3 [15,16]. In this sense, p53-mutated cells were show to be resistant to CQ-mediated cell death [16]. CQ was also shown to cause oxidative stress. Accordingly, co-treatment of NAC, a widely used antioxidant that acts as precursor of glutathione, was shown to prevent CQ-mediated glutathione depletion and redox imbalance [17]. Given the clinical potential already demonstrated by CQ in GBM therapy $[8,9]$, a better understanding of the mechanisms underlying CQ toxicity and resistance in human glioma cells may help to design new and more effective treatments.

In this sense, we investigated the molecular mechanisms and kinetics of glioma cells' responses to CQ by performing a timedependent and comparative analysis of mitochondrial accumulation, the alteration of mitochondrial membrane potential (MMP), blockage of autophagy, generation of reactive oxygen species (ROS) and DNA damage and fragmentation between four glioma cell lines that differ in their sensitivity to $\mathrm{CQ}$. We show that MMP loss, but not ROS induction, correlated to cell's susceptibility to equitoxic doses of $\mathrm{CQ}$ and that increased steady-state MMP levels could predict cells resistance to $C Q$. Interestingly, we also show that culture media acidification is an important component driving NAC-mediated protection against $\mathrm{CQ}$ and that raising $\mathrm{pH}$ values of NAC-containing media compromised, but not completely abolished, this effect. Altogether, the results point to an important ROS scavenging-independent mechanism regulating NAC-mediated protection against $\mathrm{CQ}$ and also that the ability of glioma cells to hold MMP values, but not necessarily to control ROS generation, determines cells fate upon CQ treatment.

\section{Material and methods}

\subsection{Cell culture}

U87MG, U343MG, U138MG and U251MG glioma cell lines were grown in DMEM (LGC Biotecnologia, Cotia, SP, Brazil) with 10\% FBS (Cultilab, Campinas, SP, Brazil) and $1 \%$ penicillin/streptomycin (Life Technologies, Carlsbad, CA, USA) at $37{ }^{\circ} \mathrm{C}$ in a humidified $5 \% \mathrm{CO}_{2}$ atmosphere. All cell lines were described previously [18,19].

\subsection{Drug treatment}

Approximately $3.75 \times 10^{5}, 1.25 \times 10^{5}$ or $2 \times 10^{4}$ cells were plated in $60-\mathrm{mm}, 35-\mathrm{mm}$ or 24 -well plates, respectively (TPP, Techno Plastic Products, Trasadingen, Zollstrasse, Switzerland). After $24 \mathrm{~h}$, a stock solution of chloroquine diphosphate (CQ) (Sigma-Aldrich, St. Louis, Missouri, USA) (10 mM) was prepared in MilliQ water, filter-sterilized and diluted to the desired concentrations in regular media. For N-acetyl L-cysteine (NAC) (Sigma-Aldrich) treatment, a $40 \mathrm{mM}$ stock solution was prepared by dissolving NAC in DMEM, filter-sterilized, diluted to the desired concentration in regular culture media. CQ was added after NAC working solution was fully prepared. The $\mathrm{pH}$ of the stock solution was clearly acid and $\mathrm{pH}$ was measured immediately after dissolving this drug in DMEM
$(\mathrm{pH}=4.2)$. To evaluate the effects of $\mathrm{pH}$ on cell treatment, the $\mathrm{pH}$ was adjusted (with $\mathrm{NaOH} 1 \mathrm{M})$ to DMEM regular values $(\mathrm{pH}=7.6)$. Culture media with low $\mathrm{pH}$ (in the absence of NAC) was prepared by reducing the $\mathrm{pH}$ (with $\mathrm{HCl} 6 \mathrm{M}$ ). Both solutions were processed similarly in order to prepare working solutions (10\% FBS and $1 \%$ antibiotics) and the $\mathrm{pH}$ values, immediately before adding to cells, were 6.6 for 25 mM NAC, 6.6 for "low pH media", 7.6 for "normal pH NAC", and 7.6 for regular culture media.

\subsection{Cell viability test (XTT), Sub-G1 and $\gamma-H 2 A X$ analysis by flow cytometry}

Cells were washed with PBS and incubated with XTT labeling mixture for approximately $50 \mathrm{~min}$, according to the manufacturer's instructions (Cell Proliferation Kit II XTT, Roche, Basel, Switzerland). Sub-G1 DNA and $\gamma$-H2AX content were analyzed as previously described [20]. Briefly, both adherent and detached cells were fixed with $1 \%$ formaldehyde for 15 min on ice, washed with PBS, fixed with 70\% ethanol (Labsynth, Diadema, SP, Brazil), and stored at $-20^{\circ} \mathrm{C}$. Prior to analysis, cells were blocked and permeabilized with $0.2 \%$ Triton X-100 (Sigma-Aldrich) in PBS and $1 \% \mathrm{BSA}$, then incubated with anti- $\gamma$-H2AX (Anti-phospho-Histone H2AX [ser139], clone JBW301, Upstate, Millipore, Billerica, MA, USA) and anti-mouse FITC (Sigma-Aldrich) antibodies. DNA was stained using $20 \mathrm{mg} / \mathrm{ml}$ propidium iodide (PI) (Calbiochem, Merck, Whitehouse Station, NJ, USA), $0.02 \mathrm{mg} / \mathrm{ml}$ RNase A (Life Technologies) and $0.1 \%$ Triton X-100 solution. PI (red) and $\gamma$-H2AX (green) fluorescence were measured by flow cytometry (Guava Easycyte, Millipore).

\subsection{Western blot analysis}

Cells were lysed in $50 \mathrm{mM}$ Tris pH 7.5, $20 \mathrm{mM} \mathrm{NaCl}, 1 \mathrm{mM}$ $\mathrm{MgCl}_{2}, 0.1 \%$ SDS (Sigma-Aldrich), $1 \mathrm{mM} \mathrm{Na}_{3} \mathrm{VO}_{4}$, protease inhibitor cocktail (Cocktail Set III, Calbiochem) and 0.25 units/ml benzonase (Novagen, Merck). After quantification (Bradford method, Bio-Rad Laboratories, Hercules, CA, USA), the proteins were separated on an SDS-polyacrylamide gel and blotted onto a nitrocellulose transfer membrane (GE Healthcare, Waukesha, WI, USA). Protein expression was detected using anti-LC3 (Sigma-Aldrich), anti-tubulin, anti-GAPDH or anti-TOM20 (Santa Cruz, Santa Cruz, CA, USA), anti-p62 (Cell Signaling) or anti-cleaved PARP (Abcam, Cambridge, MA, USA) antibodies. A chemiluminescent HRP substrate (Millipore) was used to develop the membranes, and the luminescence intensity was determined using an ImageQuant 300 (GE Healthcare).

\subsection{MitoTracker analysis}

Mitochondrial content was determined using the MitoTracker ${ }^{\circledR}$ Red FM Probe (Life Technologies) according to the manufacturer's instructions, with modifications. Briefly, cells were incubated with $50 \mathrm{nM}$ MitoTracker Red in regular media for $40 \mathrm{~min}$, detached with trypsin (Adolfo Lutz Institute, São Paulo, SP, Brazil), resuspended in 1\% FBS DMEM without phenol red, and the mean red fluorescence intensity was measured by flow cytometry.

\subsection{Mitochondrial membrane potential (MMP) analysis}

MMP variation was determined as previously described [21], with modifications. Cells were detached with trypsin and incubated for $15 \mathrm{~min}$ with $50 \mathrm{nM}$ tetramethylrhodamine, methyl ester perchlorate (TMRM) (Life Technologies) in PBS containing $0.1 \%$ FBS. After washing, the cells were resuspended in PBS $(0.1 \%$ FBS), and the mean yellow fluorescence intensity was measured by flow cytometry. 


\subsection{Analysis of reactive oxygen species (ROS) generation}

ROS levels were analyzed as previously described [22]. Briefly, cells were detached with trypsin and incubated for 30 min with $10 \mu \mathrm{M}$ of DCFCDA $\left(2^{\prime}, 7^{\prime}\right.$-dichlorofluorescein diacetate, Sigma-Aldrich, 35845), or for 15 min with $5 \mu \mathrm{M}$ of Mitosox (Life Technologies, M36008) in DMEM containing 0.2\% FBS and without phenol red. The mean green or red fluorescence intensity was measured by flow cytometry. Hydrogen peroxide $(1 \mathrm{mM})$ and actinomycin $\mathrm{D}$ $(10 \mu \mathrm{M})$ were used as positive controls for DCFDA and Mitosox analysis, respectively.

\subsection{DNA isolation and quantitative long PCR for DNA damage analysis}

Cells were lysed using $1 \%$ SDS and $100 \mu \mathrm{g} / \mathrm{ml}$ proteinase $\mathrm{K}$ (Sigma-Aldrich), and DNA was isolated after phenol:chloroform: isoamyl alcohol extraction (1 volume) followed by $100 \%$ ethanol precipitation (2.5 volumes). DNA was quantitated with a Quant-iT dsDNA Picogreen kit (Invitrogen, Life Technologies) using a GloMax Microplate Multimode Fluorometer (Promega, Fitchburg, MA, USA) with a Blue Optical Kit filter (Ex: $490 \mathrm{~nm}$, Em: 510-570 nM) (Promega). As previously described [23], 15 ng DNA was used for qPCR using TaKaRa LA PCR (TaKaRa Bio Group, Japan). The parameters were $85^{\circ} \mathrm{C}$ hot start addition of DNA polymerase; cycles: $94{ }^{\circ} \mathrm{C}$ for $3 \mathrm{~min} ; 29-31$ cycles of $94^{\circ} \mathrm{C}$ for $30 \mathrm{~s} ; 69^{\circ} \mathrm{C}$ for $9 \mathrm{~min} ; 4^{\circ} \mathrm{C}$ infinity. The PCR products were run on a $0.7 \%$ agarose gel and quantitated using a Quant-iT dsDNA Picogreen kit. The analysis was performed by calculating the ratio of the corrected values of fluorescence in the irradiated samples divided by that of the nonirradiated sample. The negative natural logarithm $(-\ln )$ of this ratio was calculated to determine the frequency of lesions per fragment based on a Poisson distribution and assuming that DNA damage is randomly distributed across the genome. Supplementary Table S1 provides detailed information about primers, gene length and amplified locus size.

\subsection{Alkaline comet assay}

The alkaline comet assay was performed as previously described [20] with modifications for the detection of oxidized purines with the Escherichia coli Formamido Pyrimidine-DNA Glycosylase (FPG) [24]. Briefly, after overnight lysis, the comet slides were washed in FPG glycosylase buffer (40 mM Hepes pH 7, $10 \mathrm{mM}$ $\mathrm{MgCl}_{2}, 1 \mathrm{mM}$ DTT), and incubated for $30 \mathrm{~min}$ at $37^{\circ} \mathrm{C}$ with FPG (New England Biolabs, Ipswich, MA, USA) at $8 \mathrm{U} / \mathrm{ml}$ in $1 \times$ NEBuffer 1 , supplemented with $100 \mu \mathrm{g} / \mathrm{ml}$ BSA (both supplied by the manufacturer). One half of each slide was incubated with the enzyme, while the other half was incubated with the same solution, but without the glycosylase (negative control). Experiments were performed in duplicate and twice independently. Comets were stained with ethidium bromide, imaged with a fluorescence microscope (Olympus BX51, Olympus, Center Valley, PA, USA), and at least 50 comets were scored for each condition per slide with Kinetic Imaging Komet 6.0 (Andor ${ }^{\mathrm{TM}}$ Technology, Belfast, UK).

\subsection{Mitochondrial (mt) DNA copy number analysis}

20 ng of DNA was isolated using DNeasy Blood \& Tissue Kit (QIAGEN), and submitted to a quantitative PCR reaction using the SYBR green probe, in a 7500 Real Time equipment (Life Technologies). The ratio of mtDNA (as evidence by ND1 gene amplification) to nuclear DNA (HPRT gene amplification) was used to estimate mtDNA amount per cell. Primers used were HPRT sense: TGACATGTGCCGCCTGCGAG; HPRT reverse: GTGGTCGCTTTCC GTGCCGA; ND1 sense: ACTACGCAAAGGCCCCAACG; ND1 reverse:

\section{GAGCTAAGGTCGGGGCGGTG.}

\subsection{Statistical analysis}

Statistical significance was assessed using unpaired test, oneway ANOVA or two-way ANOVA followed by the Bonferroni test (Prism 5, GraphPad Software Inc.).

\section{Results}

\subsection{Time course analysis of CQ-induced alterations in U87MG cells}

We first investigated the time-dependent mitochondrial alterations, oxidative stress (ROS levels) and the accumulation of AVs (LC3II, as a readout for autophagy impairment) in U87MG glioma cells exposed to $50 \mu \mathrm{M} C Q$. This dose reduces cell viability to approximately $10-20 \%$ after $48 \mathrm{~h}$ of continuous treatment (Fig. 1A), as measured by the Cell Proliferation Kit II (XTT). Cell viability of the glioma cell lines U343MG, U138MG and U251MG is also shown in Fig. 1A. Since this assay measures conversion of XTT to formazan by mitochondria, cell viability is used as a direct measure of mitochondrial metabolic activity. By staining mitochondria with MitoTracker (a probe capable of staining mitochondria regardless the polarization status of this organelle [25]), we noticed, by flow cytometry, a continuous increase in the content of these organelles over time (Fig. 1B). Conversely, by staining cells with TMRM, a cell-permeable cationic dye whose accumulation in the mitochondria is driven by their membrane potential, we observed, also by flow cytometry, an early and progressive loss of MMP in the presence of CQ (Fig. 1C). The generation of ROS was measured by incubating cells with DCFDA or MitoSox probes. The use of MitoSox revealed that the formation of mitochondrial superoxide occurs at early time points (Fig. 1D). In contrast, DCFDA revealed ROS induction only at later time points (48 h) of CQ treatment (Fig. 1E). Representative histograms of flow cytometry analyses (MitoTracker, TMRM, DCFDA and Mitosox) are shown in Supplementary Fig. S1. Finally, the accumulation of LC3II is evident as early as $1 \mathrm{~h}$ post-CQ treatment (Fig. 1F). This was accompanied by an accumulation of TOM20 (a mitochondrial translocase receptor located in the outer membrane of the mitochondria) confirming the increase in organelle levels over continuous CQ treatment, starting as early as $1 \mathrm{~h}$ post CQ treatment (Fig. 1F). However, we could not detect any increase in mitochondrial DNA (mtDNA) copy number in CQ-treated cells (Fig. 1G). Therefore, results suggest that CQ results in the accumulation of swollen (increased TOM20 and mitotracker staining) and dysfunctional (reduced MMP and increased mitosox staining) mitochondria, but not organelle biogenesis (Fig. 1G). In summary, we observed that CQ induced LC3II and mitochondrial accumulation, loss of MMP and mitochondrial superoxide generation are detectable at the very first hours of treatment with $\mathrm{CQ}$ and these effects increased in a time-dependent manner. Interestingly, ROS detection by DCFDA probe was only observable at a later time point.

\subsection{NAC and culture media acidification protects glioma cells from CQ toxicity}

We then investigated the effects of NAC, a widely used antioxidant, on U87MG cells co-treated with CQ. Results show that NAC drastically reduced CQ-induced loss of cell viability and MMP, DNA fragmentation, PARP cleavage, and AVS accumulation (as measured by LC3II and p62 accumulation) (Fig. 2). We also allowed cells to recover for an additional $72 \mathrm{~h}$ in complete media after CQ and/or NAC treatment, and analyzed them under a light 
A

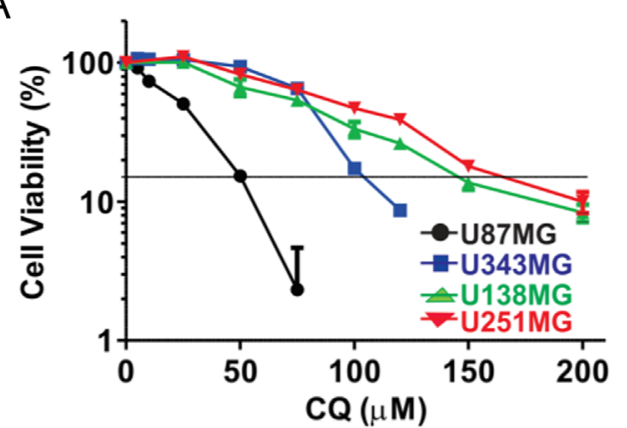

C

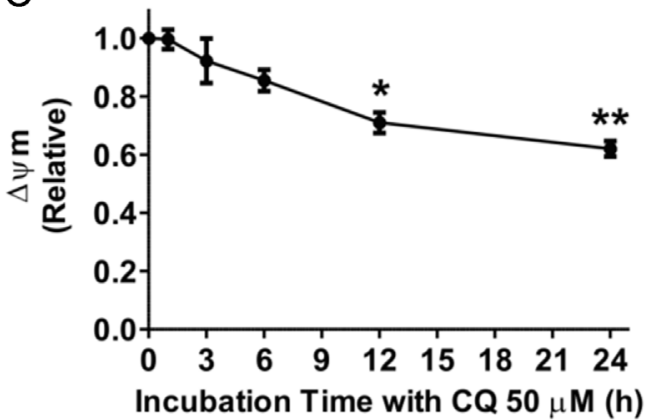

E

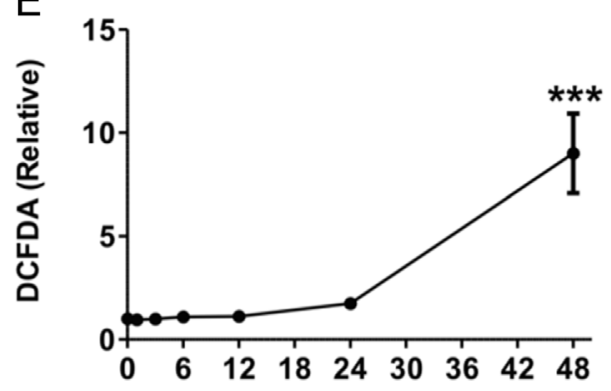

Incubation Time with CQ $50 \mu \mathrm{M}$ (h)

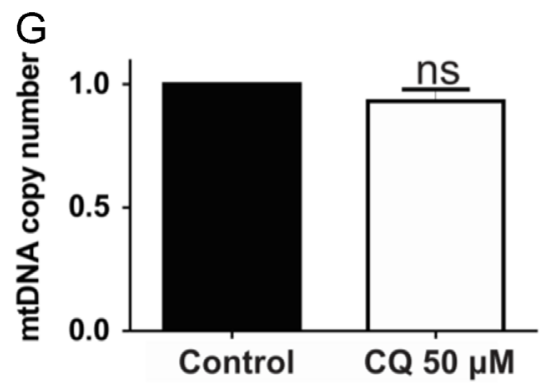

B

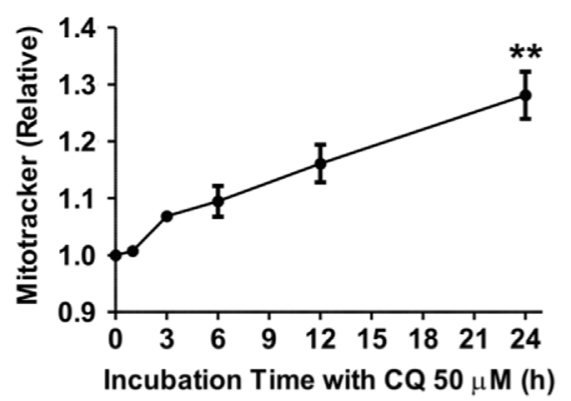

D

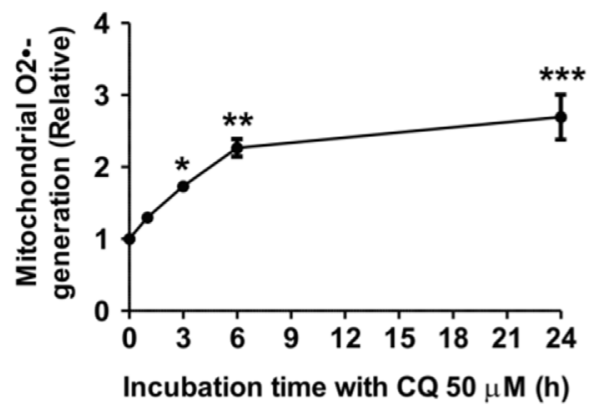

$\mathrm{F}$

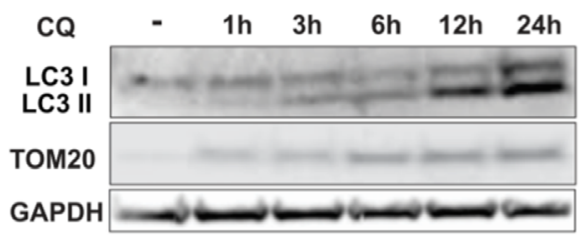

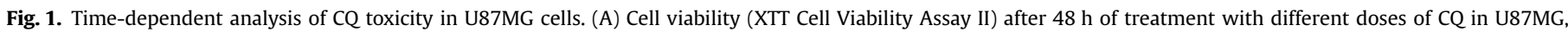

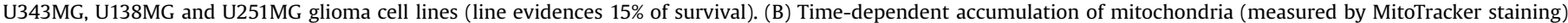

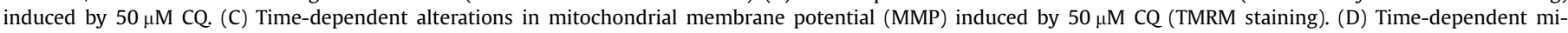

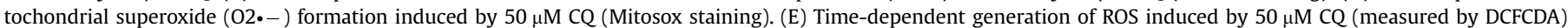

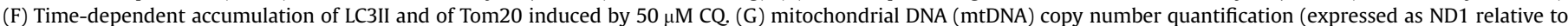
HPRT gene copies) of cells treated for $24 \mathrm{~h}$ with $50 \mu \mathrm{M}$ of CQ. ${ }^{*} p<0.05$, $^{* *} p<0.01$ and ${ }^{* * *} p<0.001$.

microscope (Fig. 2B). Representative pictures show that NAC protected cells from CQ toxicity, in strong contrast to cells treated only with $\mathrm{CQ}$ in which only sparse cells remained attached to the plate. Therefore, results show that NAC prevents not only CQ-induced cell death, but also the onset of early events induced by $C Q$. The protective effect of NAC was also observed in the U343MG, U138MG and U251MG cells (Supplementary Fig. S2).

Since NAC causes acidification of the culture media (see Section 2 for details), and that CQ loses its ability to diffuse across cell membrane once it is protonated [26], we asked whether the protective effects of NAC could be attributed to alterations in the $\mathrm{pH}$ during treatment. Therefore, we compared cell viability, MMP loss and LC3II accumulation upon CQ treatment in the presence of culture media supplemented with $25 \mathrm{mM}$ of NAC ("NAC", $\mathrm{pH}=6.6$ ); culture media with lower $\mathrm{pH}$ ("low $\mathrm{pH}$ media", $\mathrm{pH}=6.6$ ); or culture media supplemented with $25 \mathrm{mM}$ of NAC with $\mathrm{pH}$ equivalent to regular media solution value ("normal $\mathrm{pH}$ NAC", $\mathrm{pH}=7.7$ ). Interestingly, solely acidification of the culture media exerted a potent and significant protection against CQ toxicity, reduction on LC3II and MMP loss, similar to the same 

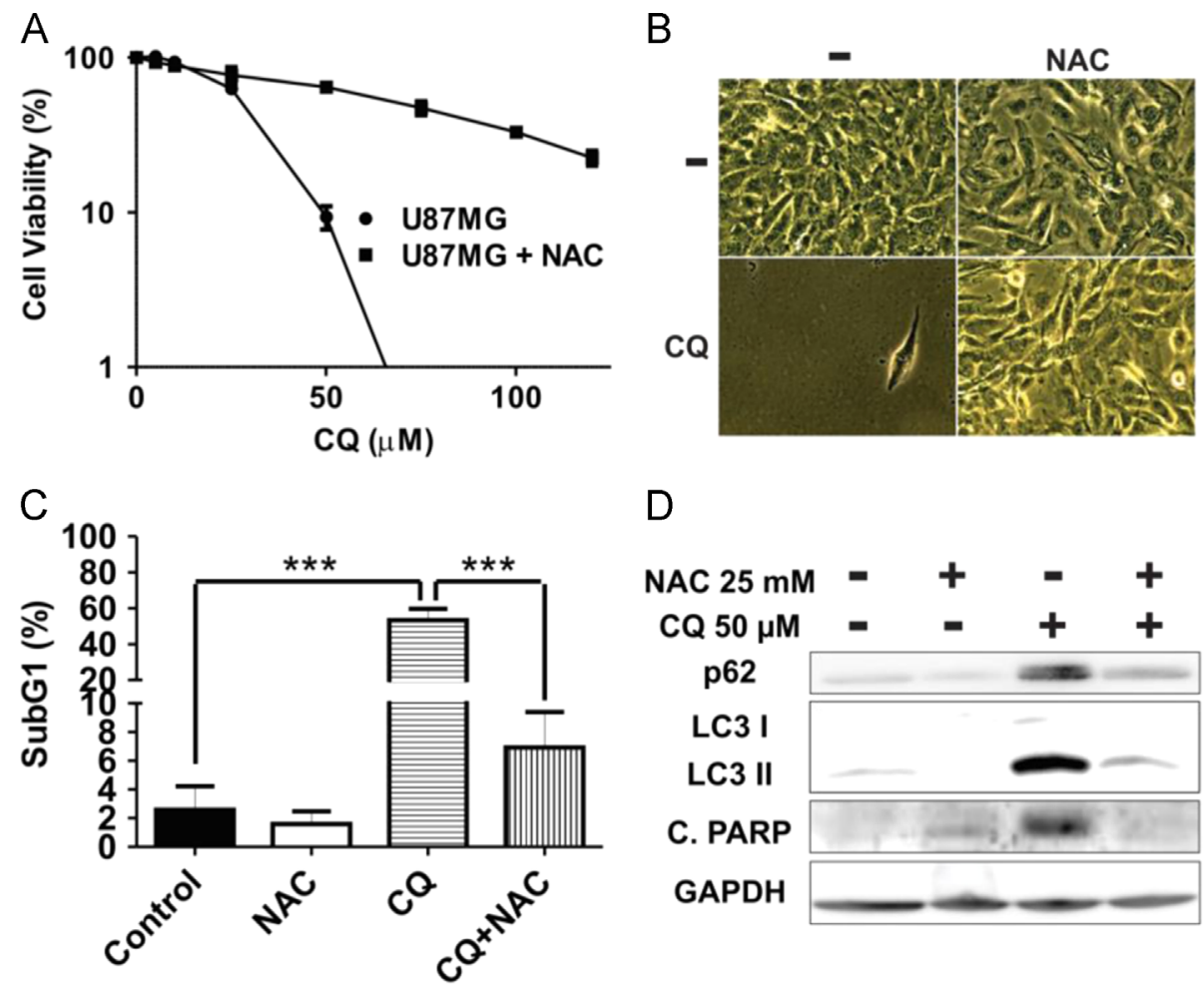

$\mathrm{D}$
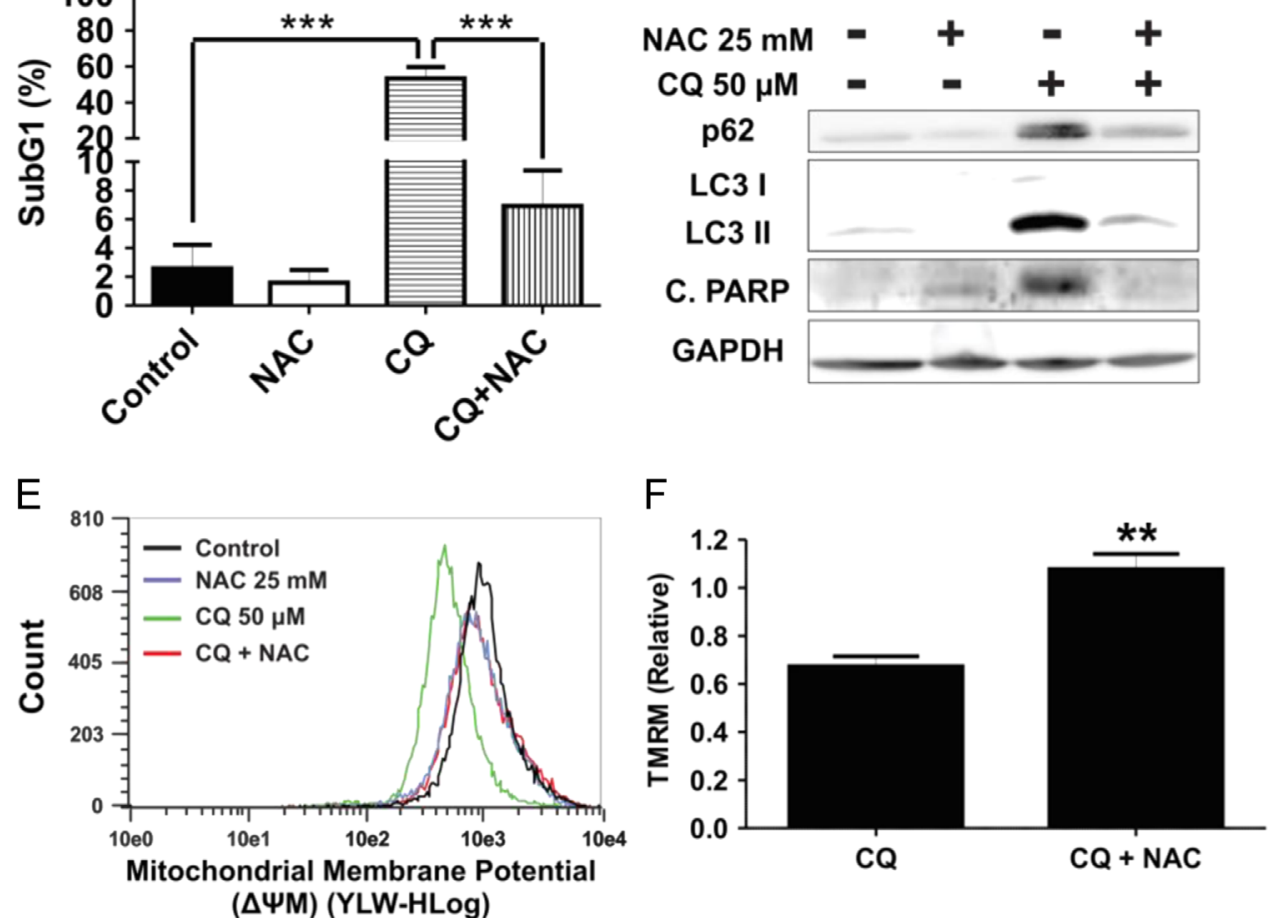

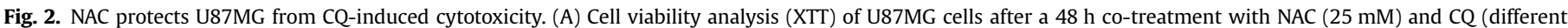

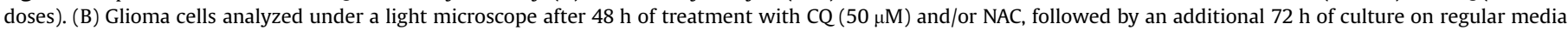

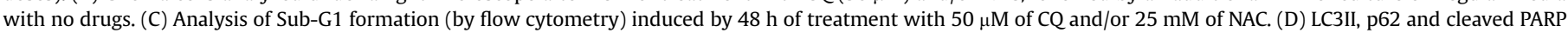

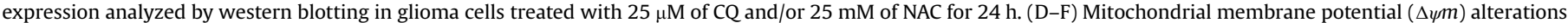
induced by $24 \mathrm{~h}$ of treatment with $50 \mu \mathrm{M}$ of CQ and/or $25 \mathrm{mM}$ of NAC (fold change of CQ-treated/untreated). ${ }^{* *} p<0.01$, ${ }^{* * *} p<0.001$.

medium containing NAC (Fig. 3). However, the protective effects of NAC were still observed in CQ-treated cells when $\mathrm{pH}$ value is adjusted. The results show that, in fact, lowering $\mathrm{pH}$ in cultured media is enough to exert a potent protective effect against CQ toxicity, and careful analyses must be taken when testing NAC in these types of experiment.

\subsection{Glioma cells' sensitivity to CQ correlates with MMP loss, but not ROS generation}

To better understand the mechanisms that drive resistance of glioma cells to $\mathrm{CQ}$, the cytotoxic effects of $\mathrm{CQ}$ were investigated in three other human glioma cell lines, comparing the accumulation of AVs and of mitochondria, ROS generation and MMP alterations. Because these cells differ in the resistance to $C Q$ these experiments were performed both at $50 \mu \mathrm{M}$ of $\mathrm{CQ}$ (common dose to all cell lines), or at equitoxic doses (i.e., capable of reducing cell viability to $10-20 \%$ after a 48 h-treatment) based on data obtained by the XTT assay (Fig. 1A). The equitoxic doses varied between cell lines ( $50 \mu \mathrm{M}$ for U87MG, $100 \mu \mathrm{M}$ for U343MG, and $150 \mu \mathrm{M}$ for both U138MG and U251MG). Results show that accumulation of mitochondria (Fig. 4A, Supplementary Fig. S1A) and of LC3II (Fig. 4E) occurred in all four cell lines after treatment with both $50 \mu \mathrm{M}$ and the equitoxic dose of $\mathrm{CQ}$ (more pronounced in this case). Interestingly, loss of MMP in the resistant cell lines, on the other hand, was achieved only after treatment with the higher, equitoxic doses (Fig. 4B, Supplementary Fig. S1B). ROS detection by the Mitosox and DCFDA probes also revealed alterations (except for DCFDA detection for U343 cells), but the changes were unrelated to the CQ toxic effects. Interestingly, the cell line U343MG failed to significantly increase ROS levels regardless the dose of CQ used (Fig. 4D and Supplementary Fig. S1D). These results indicate that loss of MMP, but not LC3II/mitochondria accumulation nor ROS generation, is achieved only upon exposure of cells to the equitoxic dose of $\mathrm{CQ}$ presenting a strong correlation with cells sensitivity to CQ. 
A
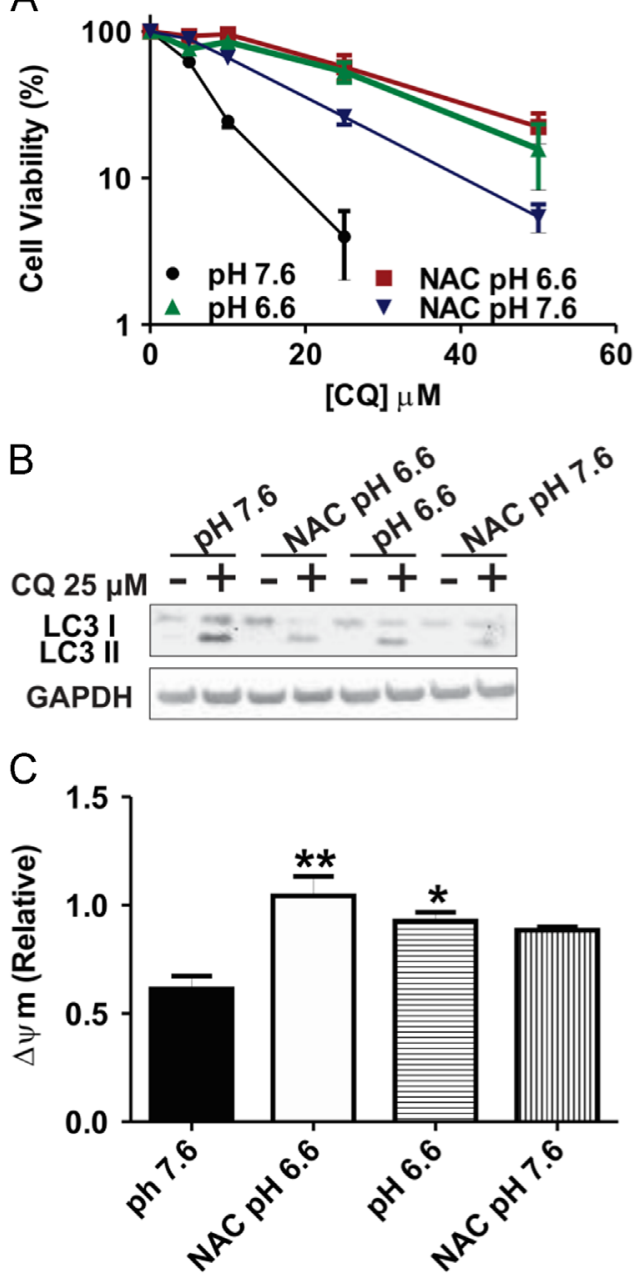

Fig. 3. NAC-induced extracellular acidification prevents CQ toxicity. (A) Cell viability (XTT) analysis of U87MG cells treated for $48 \mathrm{~h}$ with different doses of CQ diluted in culture medium with normal $\mathrm{pH}$ in the absence of $\mathrm{NAC}(\mathrm{pH} 7.6)$, normal $\mathrm{pH}$ in the presence of NAC (NAC pH 7.6), low pH in the absence of NAC ( $\mathrm{pH}$ 6.6) or low $\mathrm{pH}$ in the presence of $\mathrm{NAC}(\mathrm{NAC} \mathrm{pH} 6.6)$. ( $\mathrm{NAC}=25 \mathrm{mM}$; normal $\mathrm{pH}=7.6$; low $\mathrm{pH}=6.6)$. (B) Accumulation of LC3II in cells treated with $25 \mu \mathrm{M}$ of CQ and/or NAC (25 mM) upon the effect of normal or low pH. (C) Mitochondrial membrane potential $(\Delta y m)$ alterations (relative of CQ-treated to untreated) of cells treated with $50 \mu \mathrm{M}$ of $\mathrm{CQ}$ and/or NAC upon the effect of normal or low $\mathrm{pH}$ for $24 \mathrm{~h}$.

\subsection{Increased steady-state MMP and reduced mitochondrial content in CQ-resistant glioma cells}

We next compared the basal levels of mitochondria content, as well as MMP and ROS generation, between all four glioma cell lines. Results show that U87MG cells have significantly more mitochondria content (Fig. 5A), as well as lower MMP (Fig. 5B) than the other resistant cell lines. Interestingly, basal levels of ROS generation, when measured with the DCFDA probe, were higher in the U343MG cells than in the other glioma cell lines (Fig. 5D). On the other hand, mitochondrial superoxide generation, as measured by Mitosox, was not statistically different among the cell lines analyzed, although the U138MG seems to display lower steadystate levels between all cells tested (Fig. 5C). Therefore, we show that cell lines with increased resistance to CQ toxicity have higher steady-state levels of MMP, as well as reduced mitochondrial content, while no clear correlation between basal ROS levels and CQ sensitivity could be drawn based on analyses with neither DCFDA nor Mitosox probes.

\subsection{CQ induces purine oxidation, but not DNA strand breaks}

Loss of MMP can be elicited in response to DNA damage, activating apoptosis through the intrinsic (mitochondrial) pathway [27]. To investigate the induction of DNA damage in cells treated with $\mathrm{CQ}$ we analyzed the phosphorylation of the histone $\mathrm{H} 2 \mathrm{~A}$ variant $\mathrm{H} 2 \mathrm{AX}(\gamma-\mathrm{H} 2 \mathrm{AX})$, a commonly used marker for DNA damage, in U87MG cells exposed to $50 \mu \mathrm{M}$ CQ at different time points (Fig. 6A). We detected a mild increase in $\gamma$-H2AX at $48 \mathrm{~h}$ post-treatment. This induction of $\gamma-\mathrm{H} 2 \mathrm{AX}$ coincides with an increase in Sub-G1 cell population, possibly representing DNA fragmentation in apoptotic cells (Figs. 2C and 6B). It is important to notice that an increase in Sub-G1 in the cell lines U343MG, U138MG and U251MG could only be observed at the equitoxic doses of CQ (Fig. 6B). To rule out the presence of DNA damage at earlier time points after CQ treatment, we performed an extra long PCR on DNA extracted from U87MG cells that had been treated with $50 \mu \mathrm{M}$ of CQ for 6 or $24 \mathrm{~h}$. The presence of toxic helix-distorting lesions or DNA strand breaks, which stall polymerases $[28,29]$, would prevent the long PCR reaction from proceeding. We did not observe a significant number of DNA lesions (less than one lesion per $100 \mathrm{kbp}$ ) in the cells treated with $50 \mu \mathrm{M}$ CQ (Fig. 6C, irradiation of cells with $30 \mathrm{~J} / \mathrm{m}^{2}$ of UVC light was used as a positive control for the presence of DNA damage). These data are consistent with the absence of $\gamma-\mathrm{H} 2 \mathrm{AX}$ formation until $48 \mathrm{~h}$ after CQ treatment. We also employed the comet assay under alkaline conditions to detect the presence of strand breaks in the DNA of glioma cells treated with $50 \mu \mathrm{M}$ of chloroquine during 6 or $24 \mathrm{~h}$ (Fig. 6D). This assay was also performed after incubation of the DNA with the FPG glycosylase, which nicks DNA when damaged by several different lesions induced by oxidative stress [24]. We did not observe any significant increase in tail moment in samples not treated with FPG, confirming the absence of strand breaks in the DNA of CQ-treated samples, in agreement with the long PCR results. However, we detected a significant increase in the tail moment of the CQ-treated samples after FPG treatment (treatment of cells with $50 \mu \mathrm{M}$ of $\mathrm{H}_{2} \mathrm{O}_{2}$ for 15 min was used as a positive control for FPG activity). Results confirm that chloroquine induces oxidation of purines, but not formation of DNA strand breaks or replication-stalling lesions on the DNA of glioma cells treated with $\mathrm{CQ}$ at time points when MMP is already compromised.

\section{Discussion}

In this work, mechanisms related to glioma cells resistance to CQ were investigated. We performed a time-dependent analysis of the accumulation of AVs (LC3II) and of mitochondria, reduction of MMP, and the participation of redox processes during CQ treatment of glioma cell lines. Basically, we exposed the cells to doses of CQ that reduce cell viability to approximately $10-20 \%$ after $48 \mathrm{~h}$ of continuous treatment. Since the cell viability assay used (XTT) reflects mitochondrial enzymatic activity, we also investigated CQinduced cell death by apoptosis (Sub-G1 induction and PARP cleavage, Fig. 2), and the results confirm that loss of cell viability reflects cell death induction. Second, the data indicate that accumulation of AVs and of mitochondria with reduced MMP occurs during the very first hours of treatment. It is important to emphasize that the probe used to evaluate mitochondria content (Mitotracker Deep Red) remains bound to this organelle regardless its membrane potential. Conversely, the probe used to evaluate mitochondrial membrane potential (TMRM) display weak binding to mitochondria, and its retention on this organelle is strictly dependent on the membrane potential of it [25]. The mechanism behind MMP loss was not evaluated herein, although previous publications shed light on this issue. Lysosome membrane 
A

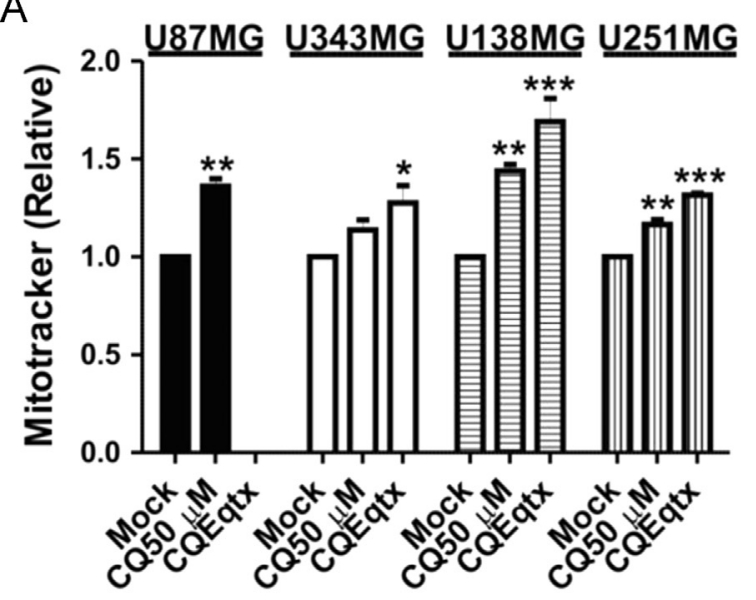

C

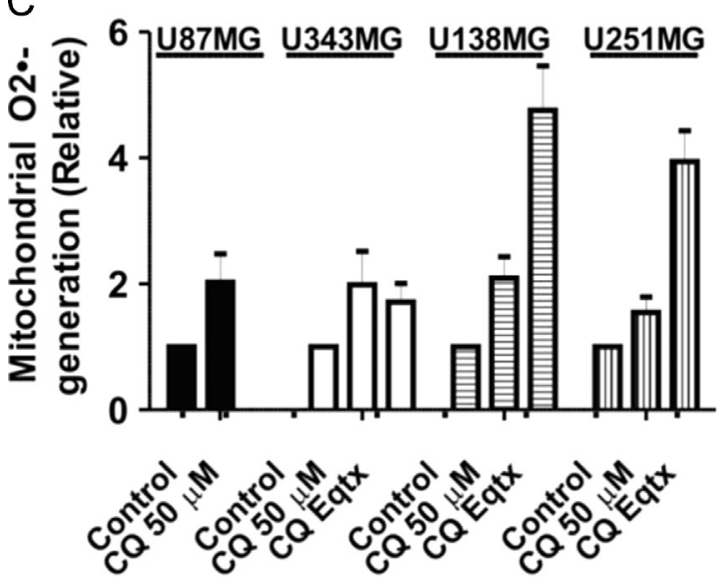

B

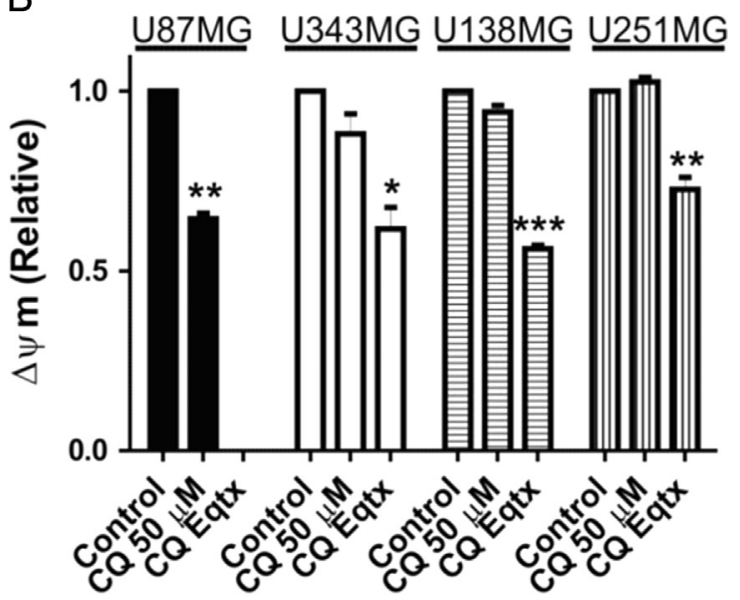

D

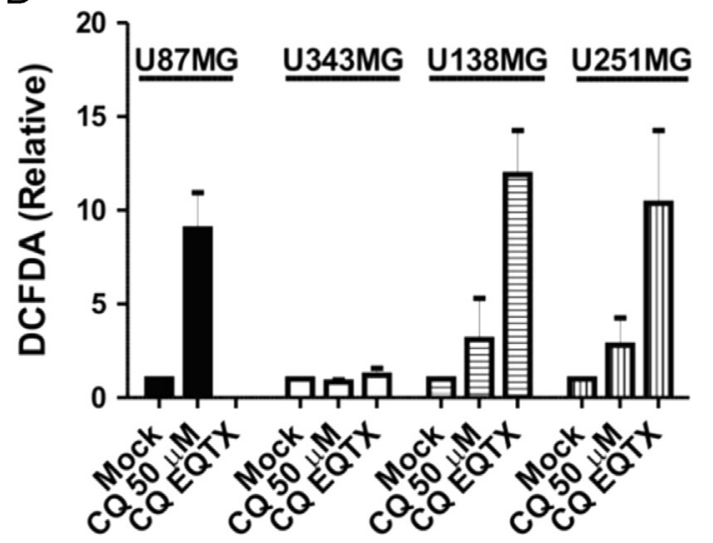

$E$

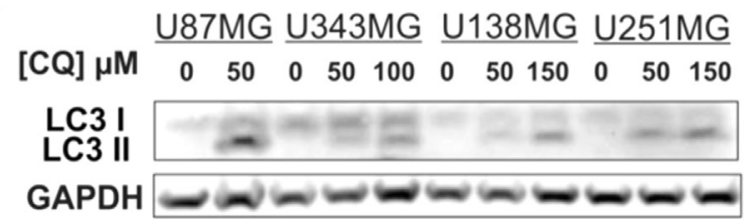

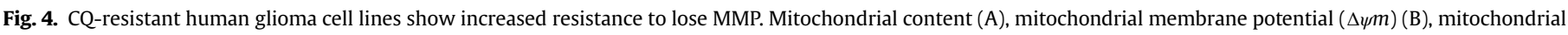

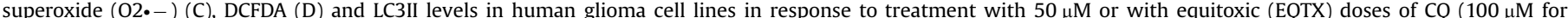

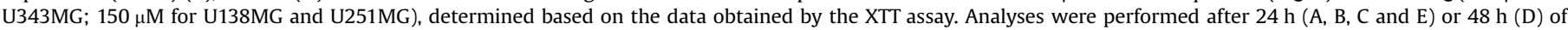
continuous treatment with CQ. Data was normalized for the untreated (control) for each cell line ${ }^{*} p<0.05$, $^{* *} p<0.01$ and ${ }^{* * *} p<0.001$.

permeabilization (LMP) elicited by CQ causes cathepsins B and D release to the cytosol. Both enzymes were shown to cleave Bid, inducing BAX translocation to the mitochondria, followed by cytochrome $\mathrm{C}$ release and loss of MMP, thereby connecting LMP to MMP $[15,30,31]$. ROS generation was detected at these very early time points when the Mitosox probe (which detects mitochondrial superoxide formation) was employed. Accordingly, we detected DNA bases oxidation upon CQ treatment, although no DNA breaks or replication blocking lesions were detected, even when MMP integrity was already compromised. On the other hand, use of DCFDA probe revealed generation of ROS only at later time points. It is important to emphasize that the DCFDA probe is oxidized to a fluorescent form and becomes trapped inside of cells. This oxidation, however, is not due to exposure to ROS in general (such as superoxide), but probably to hydroxyl radicals [32]. Thus, it is plausible that the increased DCF fluorescence we detected at later time points of CQ treatment reflect a late accumulation of hydroxyl radicals, based on conversion of early-formed mitochondrial superoxide to hydrogen peroxide (through superoxide dismutase), which is further converted to hydroxyl radicals by Fenton-type reactions. Although there is an increase in ROS generation upon CQ treatment, this event was not a good indicator of cell toxicity. For example, in the cell line U343MG, mitochondrial superoxide production showed undistinguishable levels upon treatment with $50 \mu \mathrm{M}$ (which is barely toxic) or with $100 \mu \mathrm{M}$ of CQ (which reduces cell viability to approximately $10-20 \%$ ) (Fig. 4C and Supplementary Fig. S1). For the U138MG cells, although no significant MMP loss was detected upon treatment with $50 \mu \mathrm{M}$ of CQ (which is also barely toxic for these cells), there was an important induction of mitochondrial superoxide formation to levels comparable to that observed in the U87MG cell line (Fig. 4C). Moreover, use of DCFDA probe provided no evidence of hydroxyl radicals formation in the U343MG cell line, regardless of the CQ doses used (Fig. 4D). From all parameters analyzed, only MMP loss showed a clear correlation to cell viability, where very similar levels of MMP loss were achieved for all cell lines tested upon treatment with an equitoxic dose of CQ (Fig. 4B). In this sense, it is worth pointing out that once MMP loss is achieved, occurs the release of activators of catabolic 
A

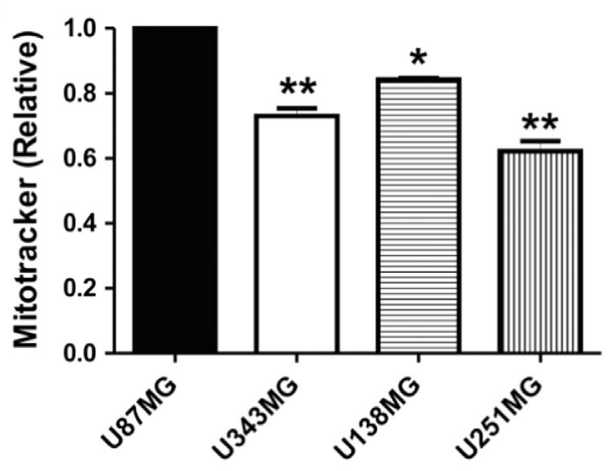

$\mathrm{B}$

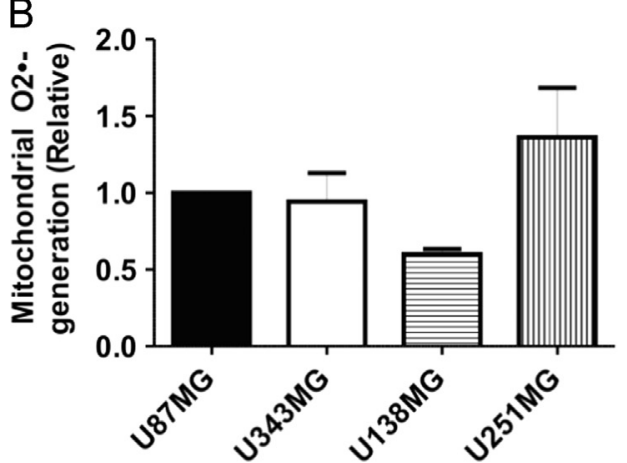

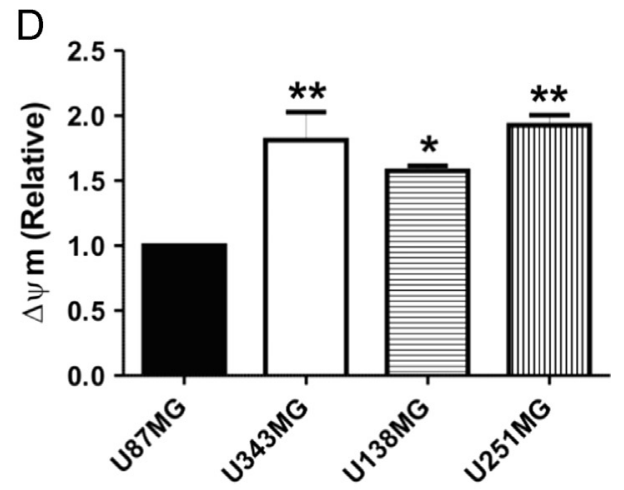

C

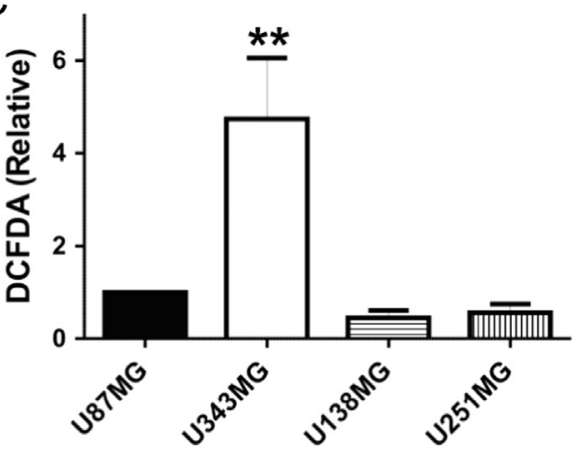

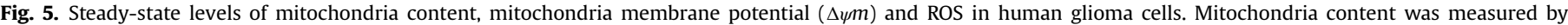

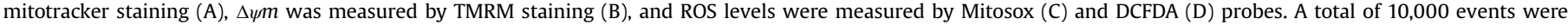
analyzed for all cell lines tested, and data are expressed as relative to U87MG cell line values. ${ }^{*} p<0.05,{ }^{* *} p<0.01$.

hydrolases (such as caspases), which promotes cell death [33].

We also noticed that U87MG cell line (the most sensitive cell line tested to $\mathrm{CQ}$ ) exhibit more mitochondrial content and lower MMP at steady-state conditions than the other (and more resistant) cell lines. These results point to a scenario in which cells with more mitochondria and/or with lower MMP are more susceptible to CQ toxicity. In this sense, it is worth pointing out that although U343MG has less mitochondria content and increased MMP than U138MG, it is more sensitive to CQ than the latter (the most resistant among the four cell lines). Since U343MG has a wild type version of the p53 protein, in contrast to U138MG and U251MG cell lines, it is possible that this characteristic renders it more susceptible to the toxic effects of $\mathrm{CQ}$ as previously shown [16]. On the other hand, the mitochondrial features, described herein, of the U343MG cells may render them more resistant to CQ than U87MG cells, also carrying functional p53 protein. Therefore, mitochondria content and MMP, together with p53, should all interplay to determine cells' susceptibility to CQ.

Addition of NAC, a widely used ROS scavenger and glutathione precursor, not only prevented CQ-induced cell death (loss of cell viability, PARP cleavage and Sub-G1 formation), but also abolished loss of MMP and LC3II accumulation (Fig. 2). However, we also noticed that NAC causes acidification of cell media when dissolved on it, and this acidification, by itself, also offered cells protection to CQ treatment. Although the acid effect was observed, NAC preparations where the $\mathrm{pH}$ was corrected still offered some cell protection, most likely due to the ability of NAC to increase glutathione levels, therefore preventing an increase in nitric oxide and oxidative stress [17]. Although speculative, it is possible that glutathione may conjugate to $\mathrm{CQ}$, and mediate its efflux out of the cell through multidrug resistant-associated protein located on the plasma membrane, in a similar manner as suggested by Raj and collaborators in their work with CQ-resistant Plasmodium falciparium strains [34]. On the other hand, the effects of media acidification are not only something to take care for experimental procedures when working with NAC, but may also have biological relevance. Recently, melanoma, colon carcinoma and osteosarcoma cells cultivated under acidic conditions were shown to have inhibited the CQ ability to block autophagy flux, although the effects on MMP were not evaluated by the authors [35]. It is known that CQ is able to diffuse across cell membrane, and becomes trapped inside acidic compartments (such as lysosomes) once it is protonated, rendering this drug lysosomotropic [26]. Thus, the protective effect elicited by NAC due to culture media acidification is probably a result of protonation of CQ outside of the cells, impairing its translocation and intracellular accumulation. Therefore, these results do not exclude that the protective effect of NAC can be elicited, at least in part, due to an increase in antioxidant defenses, but suggest caution in the interpretation of results during co-treatment of NAC with CQ. It also argues that tumor cells in poor oxygenated areas (displaying a shift to glycolysis with consequent release and accumulation of metabolic acids, promoting acidification of that microenvironment) will not respond to CQ during therapy, as recently discussed by Pellegrini et al. [35]. Therefore, it is possible that CQ may elicit a beneficial effect on glioma treatment by contributing to the loss of MMP induced by radiotherapy [36] and chemotherapy [37] restricted to cancer cells located in non-hypoxic areas of the tumors, where acidification probably does not occur.

Finally, DNA damage as measured by $\gamma-\mathrm{H} 2 \mathrm{AX}$ was only detected at a later time point ( $48 \mathrm{~h}$ ) that coincides with Sub-G1 accumulation, and thus is probably related to apoptosis. The long PCR and comet assay techniques confirmed the absence of breaks and replication blocking DNA lesions in glioma cells shortly after CQ treatment, when the loss of MMP and the accumulation of AVs and mitochondria were already detectable. Therefore, these results reinforce the idea that DNA fragmentation does not precede CQinduced cell death/loss of MMP. 

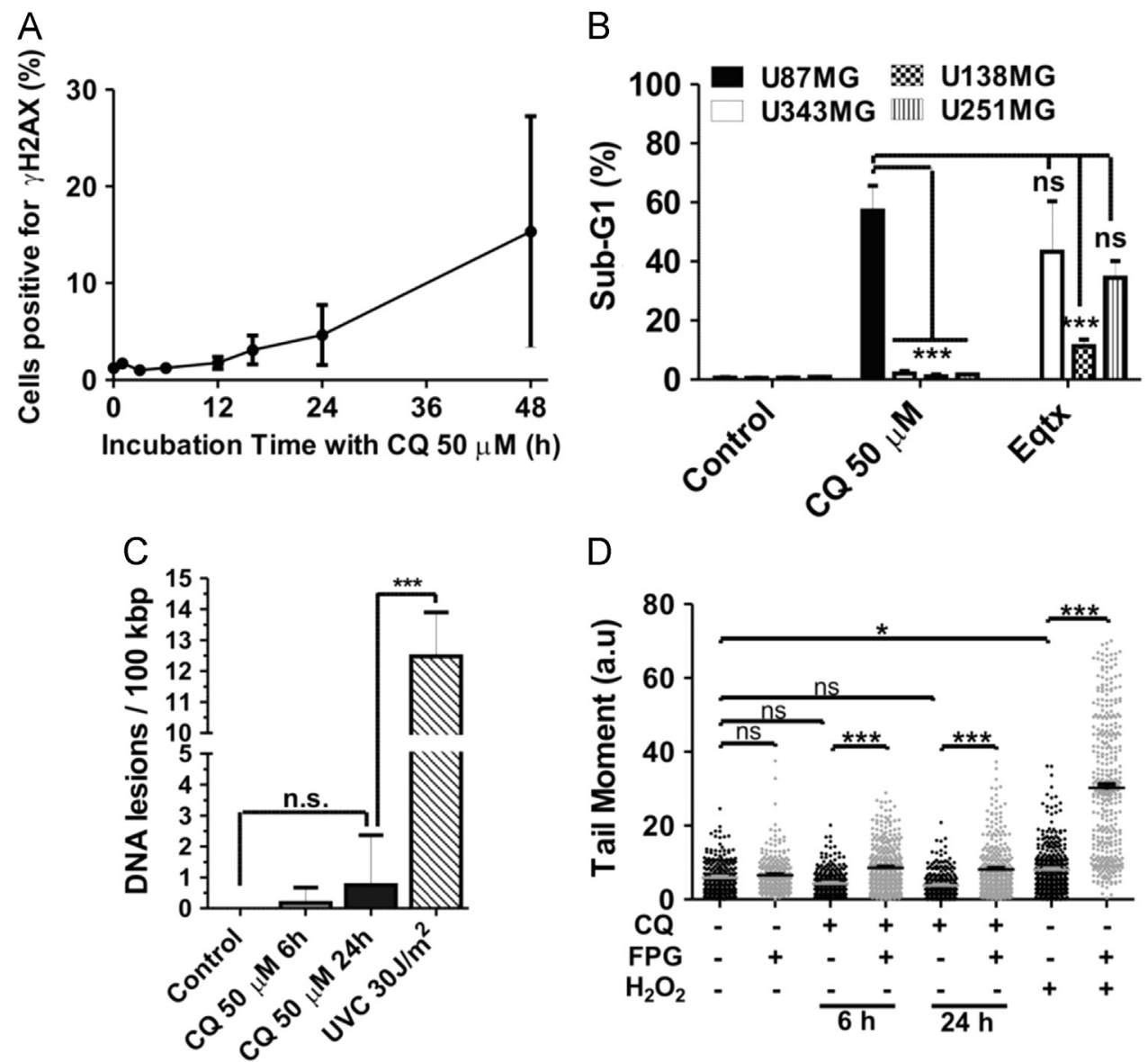

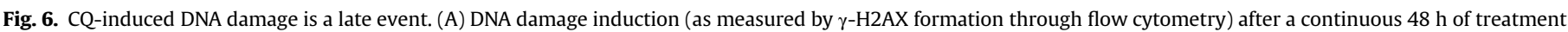
with $50 \mu \mathrm{M}$ of CQ in U87MG cells. (B) Sub-G1 formation after a $48 \mathrm{~h}$ treatment with $50 \mu \mathrm{M}$ or with equitoxic (EQTX) doses of CQ (100 $\mu \mathrm{M}$ for U343MG; $150 \mu \mathrm{M}$ for U138MG and U251MG), determined based on the data obtained by the XTT assay. (C) Detection of helix-distorting lesions or strand breaks in the DNA of U87MG cells treated with $50 \mu \mathrm{M} \mathrm{CQ}$ for 6 or $24 \mathrm{~h}$, through the quantitative long PCR method (30 J/m² of UVC was used as a positive control). (D) Detection of strand breaks by the alkaline comet assay in U87MG cells treated with $50 \mu \mathrm{M}$ CQ for 6 or $24 \mathrm{~h}$, with or without FPG treatment. ${ }^{* * *} p<0.001$.

Together, the data indicate that p53 status is not the sole responsible for glioma cell resistance to CQ treatment, pointing to an important role for glutathione, autophagy blockage and MMP in the regulation of CQ cytotoxicity in glioma cells. Moreover, since the resistance of different glioma cell lines to CQ is strictly associated to cells' ability to maintain MMP upon stress, but not necessarily to their capacity to control oxidative stress upon CQ treatment, results suggest that glutathione may also interfere in the process of CQ-induced cytotoxicity in a redox control-independent mechanism. Finally, our results suggest that assessing MMP and mitochondria content of surgery-derived tumor cells may help to predict efficacy of adding CQ to conventional GBM therapy.

\section{Conflict of interest}

The authors declare that they have no competing interests.

\section{Author's contribution}

ATV conceived initial idea, designed and carried out experiments, interpreted data, and drafted the manuscript. AQ designed and carried out experiments, interpreted data, and critically revised the manuscript. LCAL designed and carried out experiments, interpreted data, and critically revised the manuscript. DJM and CRRR carried out experiments. CCMG and DBV carried out experiments, and critically revised the manuscript. CFMM interpreted data, critically revised the manuscript, and conceived initial idea.

\section{Financial support}

Financial support was provided by the Fundação de Amparo à Pesquisa do Estado de São Paulo (Process \# 2014/15982-6 - FAPESP, São Paulo, Brazil), Conselho Nacional de Desenvolvimento Científico e Tecnológico (Process \# 304270/2013-0 - CNPQ, Brasilia, Brazil) and Coordenação de Aperfeiçoamento de Pessoal de Nível Superior (CAPES, Brasilia, Brazil).

\section{Acknowledgments}

We kindly thank Dr. Rodrigo Soares Fortunato (Federal University of Rio de Janeiro, UFRJ, Rio de Janeiro, Brazil) for critical review of the manuscript and experimental advice, and Dr. Nadja C. de Souza-Pinto (Chemistry Institute, University of Sao Paulo, SP, Brazil) for her discussion on mitochondrial detection and responses.

\section{Appendix A. Supplementary material}

Supplementary data associated with this article can be found in the online version at http://dx.doi.org/10.1016/j.freeradbiomed. 
2015.11.008.

\section{References}

[1] T.A. Dolecek, J.M. Propp, N.E. Stroup, C. Kruchko, CBTRUS statistical report: primary brain and central nervous system tumors diagnosed in the United States in 2005-2009, Neuro-Oncology (2012).

[2] S. Agnihotri, K. Burrell, A. Wolf, S. Jalali, C. Hawkins, J. Rutka, G. Zadeh, Glioblastoma, a brief review of history, molecular genetics, animal models and novel therapeutic strategies, Arch. Immunol. Ther. Exp. 61 (2013) 25-41.

[3] F. Furnari, T. Fenton, R. Bachoo, A. Mukasa, J. Stommel, A. Stegh, W. Hahn, K. Ligon, D. Louis, C. Brennan, L. Chin, R. DePinho, W. Cavenee, Malignant astrocytic glioma: genetics, biology, and paths to treatment, Genes Dev. 21 (2007) 2683-2710.

[4] D.N Louis, H Ohgaki, O.D. Wiestler, WK Cavenee, PC. Burger, A. Jouvet, B. W. Scheithauer, P. Kleihues, The 2007 WHO classification of tumours of the central nervous system, Acta Neuropathol. 114 (2007) 97-109.

[5] H. Ohgaki, P. Kleihues, The definition of primary and secondary glioblastoma, Clin. Cancer Res. 19 (2013) 764-772.

[6] R. Stupp, M. Brada, M.J. van den Bent, J.-C. Tonn, G. Pentheroudakis, Highgrade glioma: ESMO Clinical Practice Guidelines for diagnosis, treatment and follow-up, Ann. Oncol.: Off. J. Eur. Soc. Med. Oncol. 25 (Suppl. 3) (2014) iii93-iii101.

[7] R. Stupp, W. Mason, M. van den Bent, M. Weller, B. Fisher, M. Taphoorn, K. Belanger, A. Brandes, C. Marosi, U. Bogdahn, J. Curschmann, R. Janzer, S. Ludwin, T. Gorlia, A. Allgeier, D. Lacombe, G. Cairncross, E. Eisenhauer, R. Mirimanoff, Radiotherapy plus concomitant and adjuvant temozolomide for glioblastoma, N. Engl. J. Med. 352 (2005) 987-996.

[8] J. Sotelo, E. Briceño, M.A. López-González, Adding chloroquine to conventional treatment for glioblastoma multiforme: a randomized, double-blind, placebocontrolled trial, Ann. Intern. Med. 144 (2006) 337-343.

[9] E. Briceño, A. Calderon, J. Sotelo, Institutional experience with chloroquine as an adjuvant to the therapy for glioblastoma multiforme, Surg. Neurol. 67 (2007) 388-391.

[10] Y. Xu, H. Yu, H. Qin, J. Kang, C. Yu, J. Zhong, J. Su, H. Li, L.K. Sun, Inhibition of autophagy enhances cisplatin cytotoxicity through endoplasmic reticulum stress in human cervical cancer cells, Cancer Lett. 314 (2012) 232-243.

[11] X.L. Guo, D. Li, F. Hu, J.R. Song, S.S. Zhang, W.J. Deng, K. Sun, Q.D. Zhao, X.Q. Xie, Y.J. Song, M.C. Wu, L.X. Wei, Targeting autophagy potentiates chemotherapyinduced apoptosis and proliferation inhibition in hepatocarcinoma cells, Cancer Lett. 320 (2012) 171-179.

[12] A. Knizhnik, W. Roos, T. Nikolova, S. Quiros, K. Tomaszowski, M. Christmann, B. Kaina, Survival and death strategies in glioma cells: autophagy, senescence and apoptosis triggered by a single type of temozolomide-induced DNA damage, PLoS One 8 (2013) e55665.

[13] M. Degtyarev, A. De Mazière, C. Orr, J. Lin, B.B. Lee, J.Y. Tien, W.W. Prior, S. Van Dijk, H. Wu, D.C. Gray, D.P. Davis, H.M. Stern, L.J. Murray, K.P. Hoeflich, J. Klumperman, L.S. Friedman, K. Lin, Akt inhibition promotes autophagy and sensitizes PTEN-null tumors to lysosomotropic agents, J. Cell Biol. 183 (2008) 101-116.

[14] B. Ravikumar, Z. Berger, C. Vacher, C. O'Kane, D. Rubinsztein, Rapamycin pretreatment protects against apoptosis, Hum. Mol. Genet. 15 (2006) 1209-1216.

[15] Y. Geng, L. Kohli, B.J. Klocke, Ka Roth, Chloroquine-induced autophagic vacuole accumulation and cell death in glioma cells is p53 independent, Neuro-Oncology 12 (2010) 473-481.

[16] E. Kim, R. Wu, A. Ru, C. Schmitz-salue, G. Warnecke, E. Bu, N. Pettkus, D. Speidel, W. Schulz-schaeffer, W. Deppert, A. Giese, Chloroquine activates the p53 pathway and induces apoptosis in human glioma cells, Neuro-Oncology 12 (2010) 389-400.

[17] B. Park, S. Park, S. Paek, S. Park, M. Kwak, H. Choi, C. Yong, B. Yoo, J. Kim, Chloroquine-induced nitric oxide increase and cell death is dependent on cellular GSH depletion in A172 human glioblastoma cells, Toxicol. Lett. 178 (2008) 52-60.
[18] L.F.Z. Batista, W.P. Roos, M. Christmann, C.F.M. Menck, B. Kaina, Differential sensitivity of malignant glioma cells to methylating and chloroethylating anticancer drugs: P53 determines the switch by regulating xpc, ddb2,and DNA double-strand breaks, Cancer Res. 67 (2007) 11886-11895.

[19] L. Batista, W. Roos, B. Kaina, C. Menck, p53 mutant human glioma cells are sensitive to UV-C-induced apoptosis due to impaired cyclobutane pyrimidine dimer removal, Mol. Cancer Res. 7 (2009) 237-246.

[20] A. Quinet, A.T. Vessoni, C.R.R. Rocha, V. Gottifredi, D. Biard, A. Sarasin, C.F. M. Menck, A. Stary, Gap-filling and bypass at the replication fork are both active mechanisms for tolerance of low-dose ultraviolet-induced DNA damage in the human genome, DNA Repair 14 (2014) 27-38.

[21] M. Scheibye-Knudsen, M. Ramamoorthy, P. Sykora, S. Maynard, P. Lin, R. Minor, D. Wilson, M. Cooper, R. Spencer, R. de Cabo, D. Croteau, V. Bohr, Cockayne syndrome group B protein prevents the accumulation of damaged mitochondria by promoting mitochondrial autophagy, J. Exp. Med. (2012) 855-869.

[22] K. Asensi, R. Fortunato, D. dos Santos, T. Pacheco, D. de Rezende, D. Rodrigues, F. Mesquita, T. Kasai-Brunswick, A. de Carvalho, D. Carvalho, A. Carvalho, R. Goldenberg, Reprogramming to a pluripotent state modifies mesenchymal stem cell resistance to oxidative stress, J. Cell. Mol. Med. 18 (2014) 824-831.

[23] A.M. Furda, A.S. Bess, J.N. Meyer, B. Van Houten, Analysis of DNA damage and repair in nuclear and mitochondrial DNA of animal cells using quantitative PCR, Methods Mol. Biol. 920 (2012) 111-132.

[24] A.R. Collins, A.A. Oscoz, G. Brunborg I. Gaivão, L. Giovannelli, M. Kruszewski, C C. Smith, R. Štětina, The comet assay: topical issues, Mutagenesis 23 (2008) $143-151$.

[25] C. Cottet-Rousselle, X. Ronot, X. Leverve, J.F. Mayol, Cytometric assessment of mitochondria using fluorescent probes, Cytometry Part A 79A (2011) 405-425.

[26] V. Solomon, H. Lee, Chloroquine and its analogs: a new promise of an old drug for effective and safe cancer therapies, Eur. J. Pharmacol. 625 (2009) 220-233.

[27] D.R. Green, G. Kroemer, The pathophysiology of mitochondrial cell death, Science 305 (2004) 626-629.

[28] C.J. Rudolph, A.L. Upton, R.G. Lloyd, Replication fork stalling and cell cycle arrest in UV-irradiated Escherichia coli, Genes Dev. 21 (2007) 668-681.

[29] E.R. Edenberg, M. Downey, D. Toczyski, Polymerase stalling during replication, transcription and translation, Curr. Biol. 24 (2014) R445-R452.

[30] H. Appelqvist, A. Johansson, E. Linderoth, U. Johansson, B. Antonsson, R. Steinfeld, K. Kågedal, K. Ollinger, Lysosome-mediated apoptosis is associated with cathepsin D-specific processing of bid at Phe24, Trp48, and Phe183, Ann. Clin. Lab. Sci. 42 (2012) 231-242.

[31] P. Boya, K. Andreau, D. Poncet, N. Zamzami, J.-L. Perfettini, D. Metivier, D. M. Ojcius, M. Jäättelä, G. Kroemer, Lysosomal membrane permeabilization induces cell death in a mitochondrion-dependent fashion, J. Exp. Med. 197 (2003) 1323-1334

[32] M. Karlsson, T. Kurz, U.T. Brunk, S.E. Nilsson, C.I. Frennesson, What does the commonly used DCF test for oxidative stress really show? Biochem. J. 428 (2010) 183-190.

[33] G. Kroemer, L. Galluzzi, C. Brenner, Mitochondrial membrane permeabilization in cell death, Physiol. Rev. (2007) 99-163.

[34] D. Raj, J. Mu, H. Jiang, J. Kabat, S. Singh, M. Sullivan, M. Fay, T. McCutchan, X. Su, Disruption of a Plasmodium falciparum multidrug resistance-associated protein (PfMRP) alters its fitness and transport of antimalarial drugs and glutathione, J. Biol. Chem. 284 (2009) 7687-7696.

[35] P. Pellegrini, A. Strambi, C. Zipoli, M. Hägg-Olofsson, M. Buoncervello, S. Linder A. De Milito, Acidic extracellular pH neutralizes the autophagy-inhibiting activity of chloroquine: implications for cancer therapies, Autophagy 10 (2014) $1-10$.

[36] J.K. Leach, G. Van Tuyle, P. Lin, R. Schmidt-ullrich, R.B. Mikkelsen, Ionizing radiation-induced, mitochondria-dependent generation of reactive oxygen nitrogen, Cancer Res. 61 (2001) 3894-3901.

[37] C.-J. Lin, C.-C. Lee, Y.-L. Shih, C.-H. Lin, S.-H. Wang, T.-H. Chen, C.-M. Shih, Inhibition of mitochondria- and endoplasmic reticulum stress-mediated autophagy augments temozolomide-induced apoptosis in glioma cells, PLoS One 7 (2012) e38706. 